\title{
MOVIMENTO NEGRO NO BRASIL CONTEMPORÂNEO: ESTRATÉGIAS IDENTITÁRIAS E AÇÃO POLÍTICA
}

\author{
Rafael Petry Trapp ${ }^{1}$ \\ Mozart Linhares da Silva
}

\section{RESUMO}

O presente artigo visa analisar o processo de construção das estratégias identitárias e de ação política do Movimento Negro no Brasil contemporâneo. A atuação do Movimento provocou, a partir do final dos anos 70 , uma rediscussão da identidade nacional e um processo de ressignificação identitária. Nos anos 90 mudanças ocorreram no interior do Movimento Negro, que, através do diálogo com o Estado brasileiro, teve sua agenda política alçada à esfera pública. Contudo, enfatiza-se que é no contexto da participação do Movimento na Conferência Mundial contra o Racismo da ONU, realizada em Durban, na África do Sul, em 2001, que o antirracismo e a "questão racial" sofrem mudanças profundas no Brasil. No contexto pós-Durban, as "ações afirmativas" tornam-se a principal bandeira do Movimento Negro, que, paralelamente a um processo de diferenciação interna, tem seu discurso político-identitário transnacionalizado, através do deslocamento de uma identidade nacional para uma identidade étnica.

Palavras-chave: Antirracismo. Movimento Negro. Identidade Negra. Conferência de Durban.

\section{ABSTRACT}

This paper aims to analyze the process of building identity strategies and political action of the Black Movement in contemporary Brazil. The performance of the Movement led, from the late '70s, a renewed discussion of national identity and a process of redefinition of identity. In the '90s, changes occurred within the Black Movement, which, through a dialogue with the Brazilian government, had lifted its political sckedule into the public area. However, we emphasize that it is in the context of participation of the Movement in the UN`s World Conference Against Racism, held in Durban, South Africa, in 2001, which the anti-racism and the "racial question" sustained deep changes in Brazil. In the post-Durban context,

1 Acadêmico do curso de História da UNISC e bolsista PUIC voluntário, vinculado ao projeto "Movimentos Sociais Anti-racismo e Políticas Educacionais no Brasil (1970-2009): História do discurso racial e Educação como estratégia identitária", coordenado pelo Dr. Mozart Linhares da Silva, no PPGEDU/UNISC. E-mail rafaelpetrytrapp@hotmail.com

2 Doutor em História pela PUCRS, com extensão em Coimbra e Professor do Programa de Pósgraduação em Educação e do Curso de História na UNISC 
"affirmative action" becomes the main flagship of the Black Movement, which, along with a process of internal differentiation, has its political and identity discourse transnationalized, through the displacement of a nation identity to an ethnic identity.

Keywords: Anti-racism. Black Movement. Black Identity. Durban Conference.

\section{INTRODUÇÃO}

A discussão da temática do antirracismo, da identidade negra e das relações étnico-raciais no Brasil adquiriu, nas últimas décadas, uma proporção inédita, ensejando um aumento significativo na produção acadêmica e potencializando o debate público sobre o tema. Tema historicamente central na discussão da identidade brasileira, a chamada "questão racial" vem sendo pensada e elaborada das mais diversas formas, sob olhares diversos e perspectivas muitas vezes conflitantes. Um dos principais fatores que, contemporaneamente, auxiliam na tarefa de compreensão do revival das discussões concernentes à questão racial e do revigoramento de posições e lugares identitários é a emergência dos movimentos sociais antirracismo no Brasil contemporâneo.

Não há como pensar historicamente o antirracismo no Brasil sem considerar o papel fundamental que esses movimentos sociais têm tido ao longo das últimas décadas. Mais conhecidos pela denominação de "Movimento Negro", esses movimentos sociais têm uma trajetória bastante interessante e específica, no sentido de que suas reivindicações, proposições e estratégias de ação política na luta antirracista têm se constituído em inflexões importantes na história do Brasil e na maneira como se tem pensado a identidade nacional e as delicadas questões de cunho étnico-racial na constituição histórica e sociocultural brasileira.

Assim, o presente trabalho visa contribuir para o estudo da história do antirracismo no Brasil, em especial a história e atuação do Movimento Negro contemporâneo. Entende-se por Movimento Negro contemporâneo o conjunto e a pluralidade dos movimentos sociais antirracismo que têm surgido e se organizado no Brasil desde o final dos anos 1970. Pretende-se analisar neste artigo a constituição das estratégias identitárias e o processo de construção da ação política do Movimento Negro no Brasil contemporâneo, destacando a influência da Conferência Mundial contra o Racismo, realizada em Durban, na África do Sul, em 2001, e o intenso diálogo estabelecido, de um lado, entre o Movimento Negro brasileiro e o Estado brasileiro, e, de outro, com os movimentos antirracismo internacionais, sobretudo a partir do final dos anos 90.

A metodologia adotada neste trabalho basear-se-á, além de revisão bibliográfica concernente ao tema da pesquisa, na análise documental. Desta forma, tomam-se como fontes principais a produção escrita e depoimentos de militantes e intelectuais ligados ao Movimento Negro, documentos produzidos por 
esse mesmo movimento, como o Estatuto do Movimento Negro Unificado e documentos oficiais, como a Declaração Final de Durban.

O recorte temporal que se apresenta mais pertinente é o que concerne ao período de fundação do Movimento Negro Unificado (MNU) - um dos mais importantes e paradigmáticos movimentos antirracismo brasileiros -, em 1978, em São Paulo, até o ano de 2010, quando da aprovação, pelo Congresso Nacional, do Estatuto da Igualdade Racial, documento que consubstancia uma inflexão de cunho político-identitária fundamental na história contemporânea brasileira.

\section{MOVIMENTO NEGRO CONTEMPORÂNEO: IDENTIDADE E CONSCIÊNCIA NEGRA}

No final dos anos 70, surge, em todo o Brasil, uma série de movimentos sociais, com as mais diversas configurações, demandas e reivindicações. Organizados em torno da luta comum pela democracia, esses movimentos impõem-se como novos atores e forças sociais. No contexto da chamada abertura democrática, a partir dos anos 70, emerge e se organiza também uma série de movimentos e organizações sociais de caráter antirracista. Assim, em 1978, iniciase, em São Paulo, o Movimento Negro Unificado Contra a Discriminação Racial (MNUCDR).

Esse movimento reunia em si e em sua denominação outros movimentos sociais negros e/ou antirracismo. Mais tarde, denominado apenas Movimento Negro Unificado (MNU), será referência para a luta antirracista em todo o Brasil. O MNU constituiu-se como um movimento de caráter popular e democrático, e tinha como principais fins o combate ao racismo, a luta contra a discriminação racial e o preconceito de cor (MOVIMENTO NEGRO UNIFICADO apud MOURA, 1983). Em que pese o MNU reivindicar um discurso de união dos negros brasileiros, esse nunca se confirmou na prática. Nesse sentido, Silva enfatiza que

A organização do Movimento Negro brasileiro, no entanto, deve ser entendida em suas particularidades e ambiguidades. Não se pode falar de um movimento unificado e combativo desde sua fase inicial de organização (2007, p. 76).

$\mathrm{O} \mathrm{MNU}$, ao mesmo tempo em que se caracterizava como um movimento de reivindicação, protesto e denúncia das iniquidades raciais sofridas pelos negros no Brasil, pela luta contra a opressão e pela emancipação do negro, procurou desconstruir o mito e combater o discurso da chamada "democracia racial". No bojo da desconstrução do mito da democracia racial, o Movimento Negro proporá uma rediscussão da identidade nacional. A "democracia racial" constituía, a saber, o paradigma balizador da compreensão identitária nacional, especialmente a partir da década de 30 , quando das vogas modernistas no pensamento social e da presença do governo de Vargas, que arrogava união nacional. Para Silva (2007, p. $55)$, 
A democracia racial, enquanto estratégia identitária induzida politicamente, tem no período Vargas um arranjo pontuado, e visava construir um amalgama nacional que viabilizasse não só uma noção de homogeneidade nacional não-conflituada, nem mesmo de classe, mas acentuasse a idéia de povo unificado [...].

Se essa identidade e as relações étnico-raciais eram pensadas até esse momento, de maneira a conformar uma "democracia racial", a desconstrução desse mito, apoiada, além disso, em numerosas e consistentes pesquisas acadêmicas (Cf. FERNANDES, 1965; CARDOSO, 1962; HASENBALG, 1979), levará a uma problematização identitária, posto que a realidade de desigualdade entre negros e brancos tornava a ideia de "democracia racial" insustentável.

A atuação da militância e de acadêmicos e intelectuais ligados ao Movimento Negro, como Abdias do Nascimento, levou, portanto, a uma problematização e rediscussão da identidade brasileira, inserindo novos temas e questões a essa discussão, mormente a questão racial. Em contrapartida, essa articulação levou a um processo de ressignificação identitária, através da reivindicação de uma identidade e de uma consciência racial negras. A questão da consciência negra é de suma importância, no sentido de que permitiu constituir mecanismos de fortalecimento do movimento e articular o processo de ressignificação identitária entre os militantes e os negros no Brasil. Assim, para Costa (2006, p. 144),

Os conceitos 'consciência' e 'conscientização' passam a ocupar, desde a fundação do MNU, lugar decisivo na formulação das estratégias do movimento. Trata-se da tentativa de esclarecer a população negra sobre sua posição desvantajosa na sociedade, para, assim, constituir

o sujeito político da luta antirracista.

A discussão acerca da identidade nacional sofre um revés e ganha novos contornos. De uma identidade nacional ancorada na noção da não conflitualidade étnico-racial passa-se à reivindicação e à consciência de uma identidade negra, com olhos voltados para a África e para os negros da diáspora decorrente da escravidão colonial, marcados pelo passado comum de escravidão, opressão e racismo. As influências externas são muitas, mas pode-se destacar, no que se refere aos referenciais para a constituição da ação política do Movimento Negro brasileiro, os movimentos dos negros pelos direitos civis nos Estados Unidos e os africanos de caráter nacionalista, em decorrência do processo de descolonização na África. Amílcar Araújo Pereira salienta que

Embora a circulação de referenciais não fosse a mesma das décadas anteriores, é interessante perceber como o movimento negro que surge nesse momento procura informações sobre as lutas travadas por populações negras, tanto nos Estados Unidos quanto nos países africanos, para informar o próprio movimento e também para sensibilizar a sociedade brasileira sobre a questão racial no país (2008, p. 226) 
A ligação com a África torna-se central para o movimento negro também no sentido de ressignificar a identidade. A designação afro, por exemplo, tornou-se adjetivo para práticas e adscrições identitárias. Na década de 80, o discurso de ligação com a África se popularizou. Esse discurso, que começou a ser reivindicado no final década 70 , com a formação do próprio $\mathrm{MNU}$, consolida-se no contexto pós-Durban, como veremos mais adiante. A memória africana é crucial, portanto, para conformar a identidade negra e potencializar o alcance da luta do Movimento Negro (SILVA, 2007).

A experiência diaspórica torna-se essencial nesse sentido, servindo de referencial para pensar a identidade negra no Brasil e os negros onde quer que a dispersão da diáspora negra os tenha levado (Cf. GILROY, 2001). A influência de intelectuais negros é marcante para a estratégia de conscientização dos negros no Brasil. Destarte, nomes como os de Franz Fanon, Marcus Garvey, Aimé Cesaire, Léopold Senghor, entre outros, tornam-se referência constante para a militância negra brasileira (ALBERTI; PEREIRA, 2007).

A influência do Movimento Negro norte-americano, por sua vez, pode ser pensada sob vários aspectos. Além das referências de cunho estético-cultural, com o movimento Black is Beautiful e a música negra norte-americana, as práticas de ação política e as estratégias identitárias comungam de princípios comuns. Esses princípios estão em parte ancorados em algumas experiências adotadas nos Estados Unidos, qual sejam, as políticas de ações afirmativas e a adoção do paradigma multiculturalista para pensar as relações étnico-raciais no Brasil. Nesse sentido, Silva considera que

O estreitamento dos laços entre os vários Movimentos [...] com o Movimento Negro norte-americano foi, sem dúvida, um importante passo para a definição conceitual das bases unificadoras das lutas contra o racismo no mundo ocidental. (2010, pp. 12-13).

Sob a influência, portanto, desses movimentos internacionais, a luta antirracista, capitaneada pelo Movimento Negro Unificado e por outras organizações negras, potencializar-se-á no decorrer dos anos 80, na esteira das profundas transformações advindas com o restabelecimento da democracia no Brasil. Constituiu-se simbolismo importante para o Movimento Negro que o ano da aprovação da nova constituição democrática, 1988, coincidisse com o centenário da abolição da escravatura. O Movimento Negro aproveitou-se dessa data para denunciar as mazelas vividas pela população negra no Brasil e reforçar os direitos de cidadania e de igualdade legal para os afrodescendentes, para além de qualquer comemoração da Abolição, que, por sinal, foi denunciada como "farsa" (COSTA, 2006). 


\section{MOVIMENTO NEgRO E ESFERA PÚBLICA: A CAMINHO DE DURBAN}

Os anos 90 serão sumamente importantes para o Movimento Negro, pois é a partir desse período que o Movimento passará a estabelecer um diálogo intenso com o governo brasileiro. Em 1995, assumirá a presidência da República Fernando Henrique Cardoso, sociólogo da geração uspiana formada sob a guarda intelectual de Florestan Fernandes. Em 1995, ano do tricentenário da morte de Zumbi ocorre a Marcha Zumbi dos Palmares, em Brasília, com a participação de milhares de pessoas e de dezenas de movimentos e organizações antirracistas. É consenso que a Marcha representou um momento decisivo para o Movimento Negro contemporâneo. Na opinião da intelectual e militante Sueli Carneiro, a Marcha

Foi o fato político mais importante do movimento negro contemporâneo. Acho que foi um momento também emblemático, em que nós voltamos para as ruas com uma agenda crítica muito grande e com palavras de ordem muito precisas que expressavam a nossa reivindicação de políticas públicas que fossem capazes de alterar as concepções de vida da nossa gente. Foi um processo rico, extraordinário (ALBERTI; PEREIRA, 2007, p. 345).

O Governo Federal, cujo presidente foi o primeiro na história do Brasil a reconhecer publicamente a existência das iniquidades raciais em relação aos negros, propõe, em resposta às demandas do Movimento Negro apresentadas na Marcha, a criação do Grupo de Trabalho Interministerial para a Valorização da População Negra (GTI), no âmbito da Secretaria Nacional dos Direitos Humanos (SNDH). A criação desse órgão é um marco, no sentido de que aí se inicia de maneira intensa e profícua uma relação entre o governo brasileiro e o Movimento Negro, e começam a ser discutidas políticas públicas envolvendo a questão racial.

Com a participação de representantes do Movimento na SNDH e no contexto da profissionalização observada no Movimento Negro - com o surgimento de importantes ONGs antirracismo, como a Geledés e a Fala Preta! - a questão racial e as demandas do Movimento Negro entram definitivamente na pauta da agenda política nacional. Estava selada uma relação que se tornaria ainda mais forte nos anos seguintes, já no contexto de preparação para a Conferência de Durban, e que potencializaria o debate e a efetiva implementação de políticas públicas para a população negra brasileira. No âmbito da SNDH é criado, em 2000, o Comitê Nacional de preparação para a Conferência de Durban.

A atuação do comitê articulará os movimentos sociais e o governo brasileiro, através de dezenas de reuniões e seminários. Assim, as discussões giraram em torno da produção de um relatório sobre as condições de vida dos negros brasileiros e das relações étnico-raciais no Brasil, a ser apresentado na Conferência Regional das Américas, realizada em Santiago do Chile, como preparação para a Conferência Mundial de Durban. $O$ relatório enfatizava a existência de racismo e de preconceito em ralação aos negros no Brasil. Um dos 
pontos mais polêmicos do relatório foi a reivindicação de medidas de reparação e a adoção de ações afirmativas para a população negra, por parte do poder público. O Movimento Negro viveu um momento único de união em função de Durban, havendo uma articulação sem precedentes no que se refere à obtenção de consensos norteadores para a participação do Movimento na Conferência.

Convocada pela ONU em 1997, a Conferência Mundial Contra o Racismo, a Discriminação Racial, a Xenofobia e a Intolerância Correlata, foi realizada em Durban, na África do Sul, em 2001. No país de Nelson Mandela, que havia enfrentado décadas de segregação oficial, o apartheid, a ONU, governos nacionais, ONGs e movimentos sociais de todo o planeta se reuniram para discutir as questões do racismo, da intolerância e da xenofobia na contemporaneidade. Em que pese as discussões da Conferência tenham levado a tensões envolvendo a questão do sionismo e da política israelense em relação aos palestinos, 0 Movimento Negro brasileiro teve uma atuação destacada na Conferência, no sentido de que muitas de suas propostas e reivindicações encontraram eco e respaldo perante a comunidade internacional, tornando-se a Conferência um marco na história do antirracismo brasileiro.

A Conferência de Durban é significativa no sentido de que, a partir da participação da delegação brasileira no evento, houve a redefinição das estratégias de ação política para os movimentos antirracismo nacionais a partir de estratégias comuns. Muitas das reivindicações do Movimento Negro foram, inclusive, incluídas no documento final de Durban (ONU, 2002). Nesse sentido, pode-se apontar importantes mudanças na constituição do antirracismo e do Movimento Negro no Brasil no contexto pós-Durban. Considerando a importância de Durban para o antirracismo no Brasil, Costa (2006, p. 150) enfatiza que

Para a política interna brasileira, a Conferência da ONU contra o racismo de 2001 representa um importante ponto de inflexão, já que, pela primeira vez, ocorreu um debate de amplitude nacional sobre o racismo, apresentando-se novos dados e argumentos que comprovam, de forma irrefutável, a discriminação contra os afrodescendentes.

Vários são os pontos de inflexão e mudança que podem ser apontados no contexto pós-Durban. $O$ exemplo mais sintomático nesse processo são as políticas de ações afirmativas, a partir de Durban, como a principal bandeira do Movimento Negro. A questão das chamadas "cotas" passou a constituir ponto central na agenda do Movimento. Além disso, a efetiva implementação de ações afirmativas para negros - como no vestibular da UERJ, em 2002, portanto logo após a Conferência - levou a que uma das principais demandas do Movimento Negro, qual seja, a da existência de um debate público sobre a questão racial no Brasil, ocorresse em grande amplitude. Para Alberti e Pereira (2006, p. 159)

A questão das cotas e, de forma mais ampla, das ações afirmativas é, com certeza, uma novidade com um vasto potencial de mudança social, que incide não apenas sobre as possibilidades 
de estudo e trabalho de afrodescendentes, mas sobre as representações que a sociedade brasileira produz sobre si mesma, em especial as camadas média e alta, pouco acostumadas a conviver de forma igualitária com pretos e pardos. Nesse sentido, a discussão provocada pela frase incluída no documento de Durban é profícua e bem-vinda.

Observe-se também uma marcada diferenciação interna no Movimento Negro. Com o surgimento e a visibilização de várias ONGs antirracistas e o fortalecimento dos movimentos de mulheres negras - aliás, a presença brasileira mais importante na Conferência de Durban, cuja relatora foi a militante do Movimento Negro brasileiro Edna Roland - amplia-se a discussão da política da diferença no interior do próprio Movimento, que se torna mais heterogêneo. É também no contexto da Conferência que se oficializa a utilização e a positivação da designação "afrodescendente" no lugar de "negro", conforme relato de Edna Roland (apud ALBERTI; PEREIRA, 2007).

Outra questão fundamental que pode ser observada no contexto pós-Durban é o processo de transnacionalização do discurso do Movimento Negro, deslocando-se a identidade nacional para uma identidade étnico-racial. Esse processo se dá em função do relacionamento constante estabelecido entre o Movimento Negro brasileiro com outras organizações e movimentos sociais antirracismo internacionais, sobretudo latinos e norte-americanos, além do surgimento de redes de cooperação binacionais e transnacionais. Apesar disso, é interessante salientar que a questão do intercâmbio internacional já estava entre os fins do MNU desde a sua fundação (MOVIMENTO NEGRO UNIFICADO apud MOURA, 1983). Destacam-se as redes antirracistas de cooperação internacional La Alianza e a Rede Latino-Americana e Caribenha de Mulheres Negras. Nesse sentido, López assevera que

A Conferência de Durban inaugurou um momento de protagonismo dos movimentos afro-latino-americanos na arena transnacional, colocando em primeiro plano noções de justiça baseadas nas experiências diaspóricas na América Latina, que chamam a atenção para a convergência de igualdade social e pluralismo cultural (2009, p. 357).

A Conferência de Durban representa, portanto, um importante momento para a história do Movimento Negro no Brasil, pois, além da transnacionalização do discurso no sentido político-identitário, suas estratégias de ação política ganharam força ao serem traduzidas, posteriormente, na implementação de uma série de políticas públicas de caráter afirmativo (HERINGER, 2002). O debate público sobre a questão racial potencializou-se, provocando, além disso, a irrupção de posições extremadas na opinião pública e de debates acadêmicos que têm se conformado, grosso modo, na oposição entre os intelectuais racialistas e os nãoracialistas. 


\section{CONSIDERAÇÕES FINAIS}

O estudo da história do Movimento Negro contemporâneo no Brasil fornece subsídios importantes para pensar as discussões contemporâneas sobre identidade, etnicidade, racismo e cidadania, entre outros temas, e a maneira como o debate desses conceitos se relacionam com a constituição das estratégias identitárias e de construção da ação política do Movimento Negro brasileiro. Tentou-se neste trabalho entender como o Movimento Negro constrói suas estratégias de ação política. Constatou-se que uma das principais estratégias foi a de afirmar, para a militância e os negros brasileiros, a consciência de uma negritude e rediscutir a identidade nacional.

Nos anos 90 o Movimento Negro passou por intensas transformações, ao tornar-se profissional e realizar um diálogo com o Estado, processo que alçou as proposições e as demandas do Movimento para a esfera pública. $O$ que se evidencia é que, do período do governo de Fernando Henrique Cardoso aos dias atuais, o Movimento Negro tem sua articulação política potencializada. Contudo, é somente a partir da Conferência de Durban que se efetiva a transnacionalização do discurso, a partir do definitivo deslocamento de uma identidade nacional para uma étnico-racial negra. Esse processo de deslocamento identitário coaduna-se com a série de políticas públicas levadas a cabo no contexto pós-Durban, o que reafirma a importância crucial que a Conferência de Durban representa para o antirracismo, para a ação política e para a agenda do Movimento Negro no Brasil contemporâneo.

\section{REFERÊNCIAS}

ALBERTI, Verena; PEREIRA, A. Araújo (Org.). Histórias do Movimento Negro no Brasil: depoimentos ao CPDOC. Rio de Janeiro: Pallas/CPDOC-FGV, 2007.

COSTA, Sérgio. Dois Atlânticos. teoria social, anti-racismo, cosmopolitismo. Belo Horizonte: Editora UFMG, 2006.

- Política, esfera pública e novas etnicidades. Revista Internacional Interdisciplinar Interthesis, Florianópolis, v. 2, n. 1, p. 01-21, 2005.

HERINGER, Rosana. Ação afirmativa e combate às desigualdades raciais no Brasil: o desafio da prática. Encontro Nacional de Estudos Populacionais, 2002, Ouro Preto. Anais... 16 p. Disponível em: <www.abep.org.br>. Acesso em 21/06/2010.

LÓPEZ, Laura. "Que a América Latina se sincere". uma análise das políticas e das poéticas do ativismo negro em face às ações afirmativas e às reparações no Cone Sul. Porto Alegre: PPGAS/UFRGS - Tese de Doutorado, 2009.

MOVIMENTO NEGRO UNIFICADO. Estatuto do MNU. II Congresso Nacional do MNU Belo Horizonte, 1981. In: MOURA, Clóvis. Brasil: raízes do protesto negro. São Paulo: Global, 1983. 
ONU. Declaração e Plano de Ação da III Conferência Mundial de Combate ao Racismo, Discriminação Racial, Xenofobia e Intolerância Correlata. Brasília: Fundação Cultural Palmares, 2002.

PEREIRA, A. Araújo. Influências externas, circulação de referenciais e a constituição do movimento negro contemporâneo no Brasil: idas e vindas no "Atlântico Negro". Ciências e Letras. Porto Alegre, n. 44, p. 215-236, jul./dez. 2008.

SILVA, Marcelo L. da. A história no discurso do Movimento Negro Unificado: os usos políticos da história como estratégia de combate ao racismo. Campinas, SP, 2007. Dissertação. (Programa de pós-graduação em História) - UNICAMP, Campinas, 2007.

SILVA, M. Linhares da. Considerações sobre o dilema entre cor/raça/mestiçagem e ações afirmativas no Brasil. Reflexão \& Ação, Santa Cruz do Sul, v. 18, n.1, p. 08-29, 2010.

Educação, etnicidade e preconceito no Brasil. Santa Cruz do Sul: EDUNISC, 2007. 